\title{
Angular changes in implants placed in the anterior maxillae of adults: a cephalometric pilot study
}

\author{
Balazs Feher ${ }^{1,2} \cdot$ Reinhard Gruber $^{1,3}(1) \cdot$ Andre Gahleitner $^{4} \cdot$ Ales Celar $^{5} \cdot$ Philipp Luciano Necsea $^{6} \cdot$ Christian Ulm $^{2}$. \\ Ulrike Kuchler ${ }^{2}$
}

Received: 2 February 2020 / Accepted: 3 July 2020 / Published online: 13 July 2020

(C) The Author(s) 2020

\begin{abstract}
Objectives Completion of adolescent growth represents the earliest time point for implant placement, yet craniofacial growth persists into adulthood and may affect implant position. We aimed to assess whether implants placed in the anterior maxillae of adults show angular changes over time.

Material and methods We conducted a cephalometric pilot study in postpubertal patients with no growth disorders, skeletal malformations, or parafunctions. The patients received a single implant in the anterior maxilla and no orthodontic or orthognathic treatment afterwards. We measured angular changes of implants and central incisors on cephalograms taken immediately and after at least 5 years postoperatively with the Sella-Nasion line (SNL) and the nasal line (NL) as references. Changes in implantSNL angles were the primary outcome.

Results In 21 patients ( $30.2 \pm 11.5$ years at surgery) after a mean follow-up of $8.6 \pm 1.3$ years, implant-SNL angles and implant$\mathrm{NL}$ angles changed in $81 \%$ and $57 \%$ of implants, respectively. Implant-SNL changes ranged from $3^{\circ}$ counterclockwise to $4^{\circ}$ clockwise and were more prevalent in males (100\% vs. $58 \%)$ and patients under 30 at surgery ( $85 \%$ vs. $63 \%)$; mean absolute differences were larger in males $\left(1.8 \pm 1.0^{\circ}\right.$ vs. $\left.1.3 \pm 1.4^{\circ}\right)$ and patients under 30 at surgery $\left(1.5 \pm 1.4^{\circ} \mathrm{vs.} 1.1 \pm 1.4^{\circ}\right)$. Incisor-SNL angles and incisor-NL angles changed in $89 \%$ and $32 \%$ of incisors, respectively.
\end{abstract}

Conclusions Implants placed in the anterior maxillae of adults show modest angular changes over time.

Clinical relevance Changes in implant angles have potential functional and esthetic consequences.

Keywords Growth $\cdot$ Implant $\cdot$ Cephalometry $\cdot$ Pilot study

Electronic supplementary material The online version of this article (https://doi.org/10.1007/s00784-020-03445-8) contains supplementary material, which is available to authorized users.

Reinhard Gruber

reinhard.gruber@meduniwien.ac.at

1 Department of Oral Biology, University Clinic of Dentistry, Medical University of Vienna, Sensengasse 2a, 1090 Vienna, Austria

2 Department of Oral Surgery, University Clinic of Dentistry, Medical University of Vienna, Vienna, Austria

3 Department of Periodontology, School of Dental Medicine, University of Bern, Bern, Switzerland

4 Department of Radiology, University Clinic of Dentistry, Medical University of Vienna, Vienna, Austria

5 Department of Orthodontics, University Clinic of Dentistry, Medical University of Vienna, Vienna, Austria

6 Department of Dental Training, University Clinic of Dentistry, Medical University of Vienna, Vienna, Austria

\section{Introduction}

Osseointegration is a "functional ankylosis" similar to that observed in teeth following injuries [1,2]. Dental implants, like ankylosed teeth, do not follow the growth of the alveolar processes during eruption [3]. The placement of implants in growing jawbones thus results in the submersion of the implants over time, relative to adjacent erupting teeth [4]. In order to avoid this phenomenon, the earliest time point recommended for implant placement is following the end of adolescence, when growth is thought to be completed $[5,6]$. However, craniofacial growth persists into adulthood [6, 7], causing significant dimensional changes of the facial skeleton in the long term [8-10]. With regard to dental implants, the clinical implications of this residual growth have largely been underestimated $[11,12]$. Previous work has suggested vertical changes in implants as a result of continuous growth in adults $[13,14]$. Recent data have given support to these findings and 
even pointed to a potentially high prevalence of infraocclusion [15-18]. Observed in adults, the described changes could not be explained by adolescent growth.

Humans are among the few species in which an adolescent growth spurt can be observed [19]. This period of significant increase in height and weight [20] triggers major changes in the jawbones [21]. Implant therapy during adolescence is restricted to cases of extensive hypodontia [22]. Adolescence ends with the closing of the epiphyses of long bones, typically around 18 years of age in males and 15 in females [23]. Some surgical protocols consider individual variability in aging and thus recommend a more conservative approach of placing implants at a slightly higher age [24]. With most of the skeletal growth completed by the end of puberty, implant placement starting at early adulthood is generally considered safe. Nevertheless, findings on the effects of continuous craniofacial growth have raised the question whether clinically relevant changes still can occur in the adult patient.

Compared with previous work describing vertical changes [13-18], data on possible angular changes in implants due to residual craniofacial growth in adulthood are lacking. Understanding potential angular changes in implants is important for multiple reasons. In the anterior maxilla, the palatal crown surfaces of incisors guide protrusion and canines play an important role in guiding laterotrusion [25]; changes in implant angles could lead to functional issues. Moreover, implant crown esthetics play a role in achieving clinical success [26]. It is apparent that in an exposed area such as the anterior maxilla, angular changes could undermine optimal results. For these reasons, the assessment of potential angular changes in implants is also of high clinical relevance. Cephalometry is a routine radiographic tool used in orthodontics and orthognathic surgery. Structures of the head skeleton as well as their spatial relationships are routinely measured using cephalometry [27]. To understand the possible effect of residual craniofacial growth on implant angles, we applied cephalometry in this pilot study to measure long-term angular changes in implants in the anterior maxillae of adult patients. To put potential angular changes in implants in perspective, we further measured long-term changes in the angles of maxillary central incisors.

\section{Materials and methods}

\section{Experimental design}

We conducted a long-term cephalometric pilot study that was designed in accordance with the Declaration of Helsinki. This study was conducted at a single center, the Medical University of Vienna, University Clinic of Dentistry. The study protocol was approved by the ethics committee of the Medical University of Vienna (No. 2174/2018). All recruited patients were fully informed about the procedure, the materials to be used in this study, their estimated exposure to radiation, the benefits, and potential risks and complications stemming from their participation in this study. All patients gave their written consent prior to participation in this study.

\section{Inclusion and exclusion criteria}

We included patients that (i) received a single implant in the anterior maxilla (i.e., canine to canine), (ii) were at least 18 years of age at surgery, and (iii) received their implants at least 5 years prior to this study. We excluded patients with (i) birth defects with or without skeletal malformations (e.g., cleidocranial dysplasia), (ii) congenital growth disorders (e.g., congenital growth hormone deficiency), (iii) parafunctions (e.g., tongue thrust), (iv) traumatic injuries to the region of interest prior to or following implant therapy, (v) complications relating to the implant (e.g., peri-implantitis, fracture), as well as vi) orthodontic therapy, or (vii) orthognathic surgery (e.g., Le Fort osteotomy) following implant placement.

\section{Cephalometry}

We used postoperative lateral cephalograms as baseline and took one follow-up lateral cephalogram per patient. Both cephalograms were taken in the same setting and using the same parameters $(75 \mathrm{kV}, 32 \mathrm{mAs}, 3.9 \mathrm{~m}$ source-to-midsagittal-plane distance). The cephalograms were precisely standardized prior to analysis using a raster graphics editor (Photoshop, Adobe, Mountain View, CA, USA). Facial growth type was determined using Björk's sum of the saddle angle, articular angle, and gonial angle [28]. The implant axis was defined as the straight line connecting the implant shoulder to the implant apex. The long axis of the maxillary central incisor (incisor axis) was defined as the straight line connecting the incision superius incisale to the incision superius apicale. We assessed these axes in relation to two reference structures. The Sella-Nasion line (SNL) was designated as the primary reference structure due to its stability [29]. The nasal line (NL) connecting the anterior nasal spine to the posterior nasal spine was designated as the secondary reference structure. Implant-SNL, implant-NL, incisor-SNL, and incisor-NL angles were then measured in anterior direction (Figs. 1a-b). The primary outcome of this study was any change in implant-SNL angles; secondary outcomes were changes in implant-NL, incisor-SNL, and incisor-NL angles. All lateral cephalograms were evaluated by a single researcher (PLN), and all measurements were evaluated by two different researchers (BF, UK) before going into analysis. To further ensure accuracy, the measuring researcher (PLN) was calibrated by unknowingly evaluating $21 \%$ of the complete radiographic dataset twice. The duplicate measurements were then 
Fig. 1 Radiographic parameters. A Implant angles. ANS anterior nasal spine, I1 implant shoulder, I2 implant apex, N Nasion, PNS posterior nasal spine, S Sella, $\angle$ ImNL implant-NL angle, $\angle$ ImSNL implant-SNL angle. B Incisor angles. ANS anterior nasal spine, ISA incision superius apicale, ISI incision superius incisale, N Nasion, PNS posterior nasal spine, S Sella, $\angle$ InNL incisor-NL angle, $\angle$ InSNL incisor-SNL angle
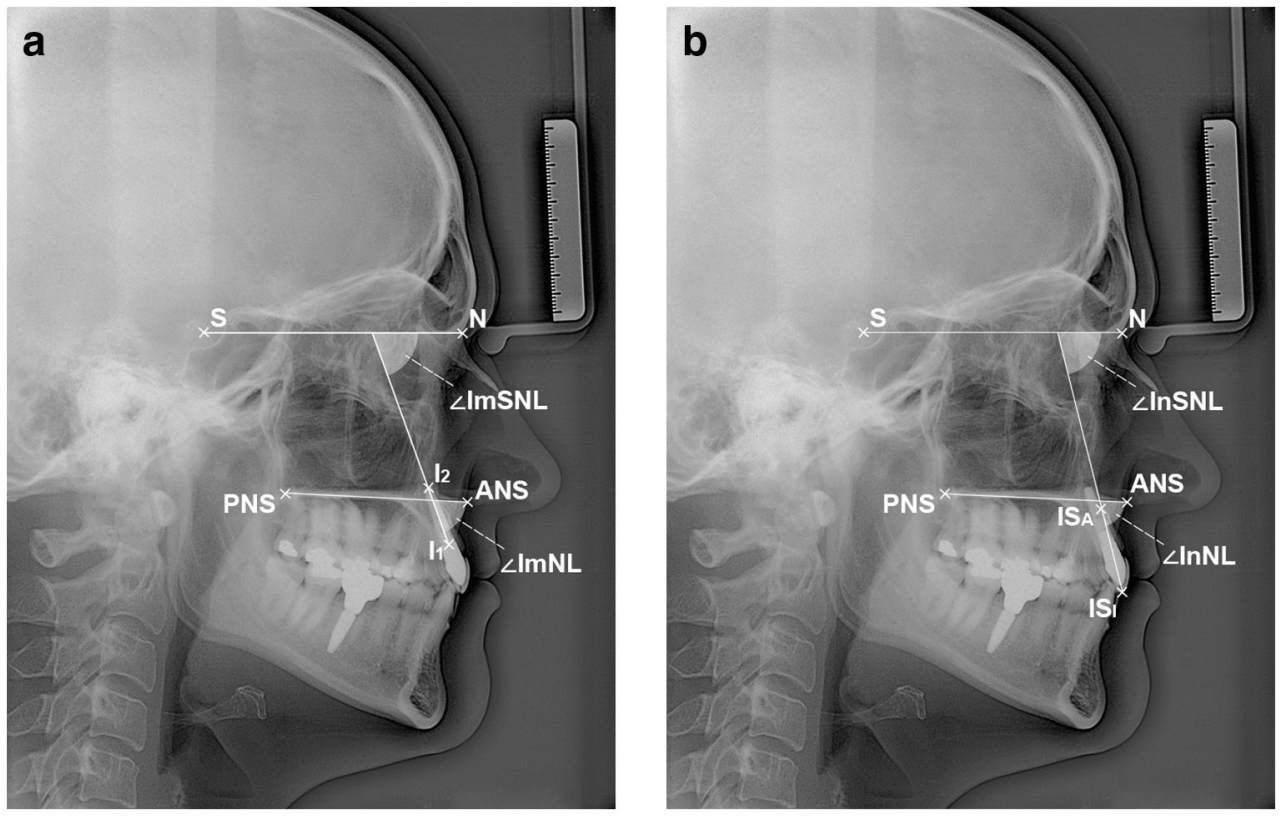

compared by a different researcher (BF). Based on the comparison of the duplicates, the intraclass correlation coefficient (ICC) of the evaluator was $99 \%$ (deviation range 0 to $1^{\circ}$ ).

\section{Statistics}

Consistent with the pilot nature of this study, no sample size was calculated prior to patient enrollment, and statistical analyses were descriptive in nature. Data were first collected in a spreadsheet (Excel 16.29.1 for Mac, Microsoft Corporation, Redmond, WA, USA), checked for possible errors, and consequently analyzed using the R statistical computing environment (Version 3.6.1, R Core Team, Vienna, Austria). Descriptive statistical methods were used for subject characteristics and basic comparisons of subgroups (e.g., sex and age distribution). Mean values and standard deviations (SDs) were calculated for numerical variables. Kernel density estimates and histograms were used to visualize numerical variables (Supplementary Figures 1a-c). Linear regression analysis was further used to assess changes in the implant angles between baseline and follow-up. The implant angle at follow-up was set as the dependent variable, with the implant angle at baseline, sex, age, Björk's angle sum, facial growth type, and follow-up time serving as independent variables.

\section{Results}

\section{Study population}

A total of 21 patients (mean age at follow-up: $38.9 \pm 11.2$ years, age range $26-58$ years, $57 \%$ female) completed the study after a mean follow-up time of $8.6 \pm 1.3$ years (range 6.6-10.9 years).
The patients' mean age at surgery was $30.2 \pm 11.5$ years (range $18-52$ years). With regard to facial growth type, $67 \%$ of patients was brachyfacial (mean Björk's sum $385.3 \pm 4.2^{\circ}$, range 376 $390^{\circ}$ ), $24 \%$ was mesofacial (mean Björk's sum $395.0 \pm 2.1^{\circ}$, range $\left.392-397^{\circ}\right)$, and $10 \%$ was dolichofacial $\left(401.5 \pm 0.7^{\circ}\right.$, range $401-402^{\circ}$ ). Subject characteristics are presented in Table 1 and Supplementary Figures 1a-c.

\section{Changes in implant angles}

To investigate angular changes in implants, we compared implant-SNL and implant-NL angles between baseline and follow-up radiographs. With regard to implant-SNL angles, changes were found in $81 \%$ of implants. A counterclockwise rotation (- ${ }^{v e}$ angular change) was found in $62 \%$ of implants

Table 1 Subject characteristics

\begin{tabular}{ll}
\hline Total study population, $n$ & 21 \\
\hline Sex, $n(\%)$ & $12(57)$ \\
Females & $9(43)$ \\
Males & \\
Age, mean \pm SD (range) in years & $30.2 \pm 11.5(18-52)$ \\
At surgery & $38.9 \pm 11.2(26-58)$ \\
At follow-up & \\
Growth type, $n(\%)$ & $14(67)$ \\
Brachyfacial & $5(24)$ \\
Mesofacial & $2(10)$ \\
Dolichofacial & $8.6 \pm 1.3(6.6-10.9)$ \\
Follow-up, mean \pm SD (range) in years &
\end{tabular}

$S D$ standard deviation 
$\left(\right.$ mean $\pm \mathrm{SD}-1.8 \pm 1.0^{\circ}$, range -1 to $\left.-3^{\circ}\right)$. A clockwise rotation ( ${ }^{v e}$ angular change) was found in $19 \%$ of implants (mean $\pm \mathrm{SD} 2.4 \pm 1.1^{\circ}$, range 1 to $4^{\circ}$ ). No changes in implantSNL angles were found in $19 \%$ of implants. Changes in implant-SNL angles were more prevalent in males than in females (100\% vs. 58\%). Mean absolute differences between baseline and follow-up were also larger in males than in females $\left(1.8 \pm 1.0^{\circ}\right.$ vs. $\left.1.3 \pm 1.3^{\circ}\right)$. Changes in implant-SNL angles were more prevalent in patients under 30 at surgery than patients at least 30 years old at baseline ( $85 \%$ vs. $63 \%)$. Mean absolute differences between baseline and follow-up were slightly larger between patients under 30 and patients at least 30 years old at surgery $\left(1.5 \pm 1.4^{\circ}\right.$ vs. $\left.1.1 \pm 1.4^{\circ}\right)$.

With regard to implant-NL angles, changes were found in $57 \%$ of implants. A counterclockwise rotation ( ${ }^{v e}$ angular change) was found $29 \%$ of implants (mean \pm SD $-1.7 \pm$ $1.2^{\circ}$, range -4 to $-1^{\circ}$ ). A clockwise rotation (+ ${ }^{v e}$ angular change) was found in $29 \%$ of implants (mean \pm SD $1.5 \pm$ $0.4^{\circ}$, range 1 to $3^{\circ}$ ). No changes in implant-NL angles were found in $43 \%$ of implants. Changes in implant-NL angles were more prevalent in males than females (78\% vs. $42 \%$ ). Mean absolute differences between baseline and follow-up were slightly larger in males than in females $\left(1.0 \pm 0.7^{\circ}\right.$ vs. $\left.0.8 \pm 1.3^{\circ}\right)$. Changes in implant-NL angles were slightly more prevalent in patients at least 30 years old at baseline than patients under 30 at surgery (63\% vs. 54\%). Mean absolute differences between baseline and follow-up did not vary between patients under 30 and patients at least 30 years old at surgery $\left(0.9 \pm 1.3^{\circ}\right.$ vs. $\left.0.9 \pm 0.8^{\circ}\right)$. A summary of changes in implant angles is presented in Table 2.

\section{Changes in incisor angles}

To put the changes in implant angles in perspective, we compared the incisor-SNL and incisor-NL angles between baseline and follow-up radiographs. Incisor angles could not be assessed in 2 patients due to missing incisors at follow-up. With regard to incisor-SNL angles, changes were found in $89 \%$ of incisors (range -5 to $4^{\circ}$ ). Changes in incisor-SNL angles were slightly more prevalent in males than females ( $100 \%$ vs. $83 \%$ ) as well as in patients at least 30 years old at baseline than patients under 30 at surgery (100\% vs. $83 \%$ ). With regard to incisor-NL angles, changes were found in $32 \%$ of incisors (range -4 to $3^{\circ}$ ). Changes in incisor-NL angles were slightly more prevalent in females than males (42\% vs. $33 \%$ ) as well as in patients under 30 at surgery than patients at least 30 years old at baseline (33\% vs. 29\%). A summary of changes in incisor angles is presented in Table 3 .

\section{Linear regression analysis}

To further analyze changes in implant angles as well as determine whether demographic or growth-related factors could have an effect on them, we applied linear regression analysis to implant-SNL angles in an explorative manner. The analysis returned a slope of regression of $0(p<0.001)$ (Fig. 2). Further, none of the assessed predictors (implant angle at baseline, sex, age, Björk's angle sum, facial growth type, and follow-up time) had an influence on the implant angle at follow-up.

Table 2 Changes in implant angles

\begin{tabular}{|c|c|c|c|c|c|c|c|c|}
\hline & \multicolumn{4}{|c|}{ Implant-SNL angle } & \multicolumn{4}{|c|}{ Implant-NL angle } \\
\hline & $\begin{array}{l}\text { Prevalence } \\
(\%)\end{array}$ & $\begin{array}{l}\text { Range } \\
\text { (deg.) }\end{array}$ & $\begin{array}{l}\text { Mean } \pm \text { SD } \\
\text { (deg.) }\end{array}$ & $\begin{array}{l}\text { Abs. mean } \pm \text { SD } \\
\text { (deg.) }\end{array}$ & $\begin{array}{l}\text { Prevalence } \\
(\%)\end{array}$ & $\begin{array}{l}\text { Range } \\
\text { (deg.) }\end{array}$ & $\begin{array}{l}\text { Mean } \pm \text { SD } \\
\text { (deg.) }\end{array}$ & $\begin{array}{l}\text { Abs. mean } \pm \text { SD } \\
\text { (deg.) }\end{array}$ \\
\hline \multicolumn{9}{|l|}{ Sex } \\
\hline Female & 67 & -4 to 3 & $-0.5 \pm 1.8$ & $1.3 \pm 1.3$ & 42 & -4 to 3 & $0.0 \pm 1.6$ & $0.8 \pm 1.3$ \\
\hline Male & 100 & -3 to 3 & $-0.9 \pm 1.9$ & $1.8 \pm 1.0$ & 78 & -2 to 2 & $-0.1 \pm 1.3$ & $1.0 \pm 0.7$ \\
\hline \multicolumn{9}{|l|}{ Age groups } \\
\hline$<20$ at surgery & 100 & -2 to 3 & $0.2 \pm 2.2$ & $1.8 \pm 0.9$ & 60 & -1 to 3 & $0.6 \pm 1.5$ & $1.0 \pm 1.2$ \\
\hline $\begin{array}{l}20-29 \text { at } \\
\text { surgery }\end{array}$ & 63 & -4 to 3 & $-0.2 \pm 2.0$ & $1.2 \pm 1.5$ & 50 & -4 to 1 & $-0.1 \pm 1.6$ & $0.9 \pm 1.4$ \\
\hline $\begin{array}{l}30-39 \text { at } \\
\text { surgery }\end{array}$ & 100 & $\begin{array}{c}-1.5 \text { to } \\
-1\end{array}$ & $-1.3 \pm 0.4$ & $1.3 \pm 0.4$ & 50 & -1 to 0 & $-0.5 \pm 0.7$ & $0.5 \pm 0.7$ \\
\hline$\geq 40$ at surgery & 83 & -3 to 0 & $-1.8 \pm 1.2$ & $1.8 \pm 1.2$ & 67 & -2 to 2 & $-0.3 \pm 1.4$ & $1.0 \pm 0.9$ \\
\hline \multicolumn{9}{|c|}{ Growth type } \\
\hline Brachyfacial & 79 & -4 to 3 & $-0.4 \pm 2.0$ & $1.6 \pm 1.2$ & 57 & -4 to 3 & $-0.2 \pm 1.5$ & $0.9 \pm 1.2$ \\
\hline Mesofacial & 80 & -3 to 0 & $-1.7 \pm 1.3$ & $1.7 \pm 1.3$ & 60 & -2 to 2 & $0.2 \pm 1.5$ & $1.0 \pm 1.0$ \\
\hline Dolichofacial & 100 & -0.5 to 1 & $0.3 \pm 1.1$ & $0.8 \pm 0.4$ & 50 & 0 to 1 & $0.5 \pm 0.7$ & $0.5 \pm 0.7$ \\
\hline
\end{tabular}

Abs. absolute, deg. degree, $N L$ nasal line, $S D$ standard deviation, $S N L$ Sella-Nasion line 
Table 3 Changes in incisor angles

\begin{tabular}{|c|c|c|c|c|c|c|c|c|}
\hline & \multicolumn{4}{|c|}{ Incisor-SNL angle } & \multicolumn{4}{|c|}{ Incisor-NL angle } \\
\hline & $\begin{array}{l}\text { Prevalence } \\
(\%)\end{array}$ & $\begin{array}{l}\text { Range } \\
\text { (deg.) }\end{array}$ & $\begin{array}{l}\text { Mean } \pm \text { SD } \\
\text { (deg.) }\end{array}$ & $\begin{array}{l}\text { Abs. mean } \pm \text { SD } \\
\text { (deg.) }\end{array}$ & $\begin{array}{l}\text { Prevalence } \\
(\%)\end{array}$ & $\begin{array}{l}\text { Range } \\
\text { (deg.) }\end{array}$ & $\begin{array}{l}\text { Mean } \pm \text { SD } \\
\text { (deg.) }\end{array}$ & $\begin{array}{l}\text { Abs. mean } \pm \text { SD } \\
\text { (deg.) }\end{array}$ \\
\hline \multicolumn{9}{|l|}{ Sex } \\
\hline Female & 83 & -5 to 4 & $-0.1 \pm 2.4$ & $1.7 \pm 1.6$ & 42 & -4 to 3 & $0.0 \pm 1.7$ & $0.8 \pm 1.5$ \\
\hline Male & 100 & -2 to 3 & $0.0 \pm 1.8$ & $1.6 \pm 0.7$ & 33 & -3 to 3 & $0.2 \pm 1.6$ & $0.9 \pm 1.4$ \\
\hline \multicolumn{9}{|l|}{ Age groups } \\
\hline$<20$ at surgery & 100 & -5 to 1 & $-0.8 \pm 2.7$ & $2.0 \pm 1.7$ & 20 & -4 to 0 & $-0.8 \pm 1.8$ & $0.8 \pm 1.8$ \\
\hline $\begin{array}{l}20-29 \text { at } \\
\text { surgery }\end{array}$ & 71 & 0 to 4 & $1.6 \pm 1.5$ & $1.6 \pm 1.5$ & 43 & 0 to 3 & $0.9 \pm 1.2$ & $0.9 \pm 1.2$ \\
\hline $\begin{array}{l}30-39 \text { at } \\
\text { surgery }\end{array}$ & 100 & -1 to 1 & $0.0 \pm 1.4$ & $1.0 \pm 0.0$ & 0 & - & - & - \\
\hline$\geq 40$ at surgery & 100 & -2 to -1 & $-1.6 \pm 0.5$ & $1.6 \pm 0.5$ & 40 & -3 to 3 & $0.0 \pm 2.1$ & $1.2 \pm 1.6$ \\
\hline \multicolumn{9}{|c|}{ Growth type } \\
\hline Brachyfacial & 92 & -2 to 3 & $0.3 \pm 1.6$ & $1.3 \pm 0.8$ & 8 & 0 to 1 & $0.1 \pm 0.3$ & $0.1 \pm 0.3$ \\
\hline Mesofacial & 80 & -2 to 4 & $-0.2 \pm 2.5$ & $1.8 \pm 1.5$ & 60 & -3 to 3 & $0.6 \pm 2.5$ & $1.8 \pm 1.6$ \\
\hline Dolichofacial & 100 & -5 to 1 & $-2.0 \pm 4.2$ & $3.0 \pm 2.8$ & 100 & -4 to 2 & $-1.0 \pm 4.2$ & $3.0 \pm 1.4$ \\
\hline
\end{tabular}

$A b s$. absolute, deg. degree, $N L$ nasal line, $S D$ standard deviation, $S N L$ Sella-Nasion line

\section{Discussion}

Evidence on long-term changes in implant positions in adult patients is accumulating. Following early data from preclinical models [4, 30] and clinical studies in adolescents [31], findings from adults have substantiated the possibility of vertical

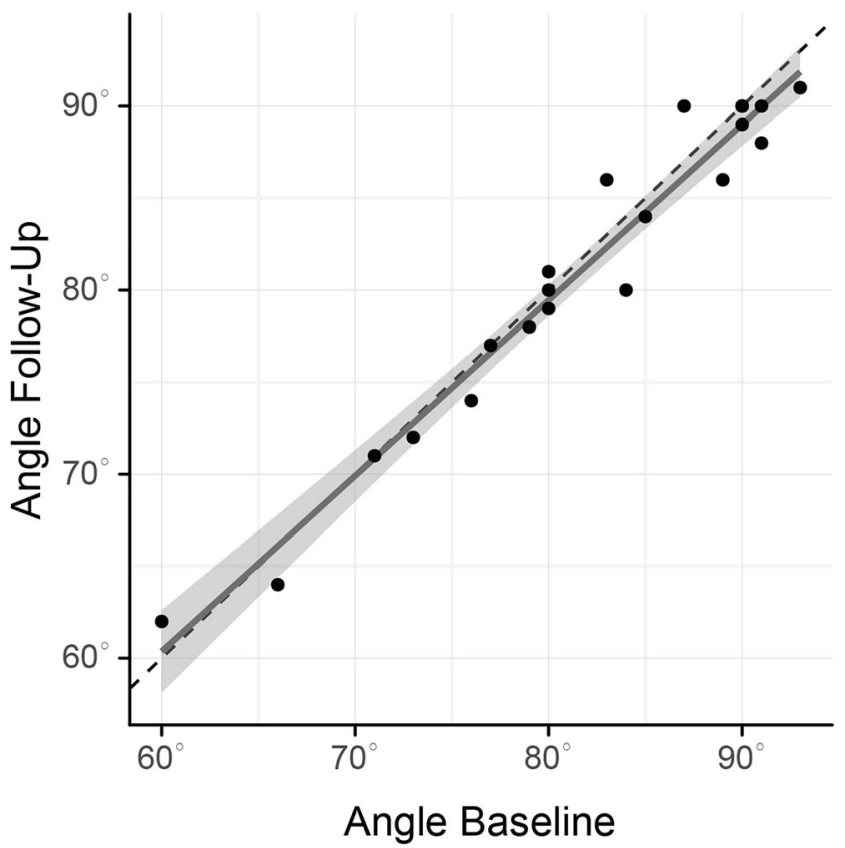

Fig. 2 Linear regression analysis. The dashed line shows no change. The dark gray line represents the regression line. The light gray area surrounding the dark gray line represents the corresponding $95 \%$ confidence interval. Slope of regression $=0(p<0.001)$ changes in implant position, up to the point of infraocclusion [13-16]. The present pilot study is the first to report angular changes in implants over the course of adulthood. Based on a cephalometric analysis, we found that after a mean follow-up time of 8.6 years, $81 \%$ of implants placed in the anterior maxillae showed modest rotational changes ranging from $3^{\circ}$ counterclockwise to $4^{\circ}$ clockwise with reference to the SNL and $57 \%$ of implants showed rotational changes with reference to the NL. These findings are important for they show the possibility of angular changes in implants placed in adult patients. We further found that the prevalences, ranges, and means of implant-SNL and incisor-SNL angles showed similarities over time. Across both implants and natural incisors, SNLreferenced angles showed more prevalent and larger changes overall than NL-referenced angles. Taken together, these findings suggest that residual craniofacial growth could affect the maxilla as a whole and the angular changes cannot be explained solely by the continuous development of the alveolar process.

Our primary findings relate to those of others as at $81 \%$, the prevalence of changes in implant-SNL angles in our patient cohort is comparable to that of vertical changes (73\%) described recently [16]. In our patient cohort, changes in implant-SNL angles were found in $58 \%$ of females and $100 \%$ of males and changes in implant-NL angles were found in $42 \%$ of females and $78 \%$ of males. These sex differences are in contrast to the findings of others as with just one exception [32], previous work did not identify a predisposing role of sex on vertical changes in implants $[13,17,18,33]$. With regard to age at surgery, changes in implant-SNL angles were 
found in $85 \%$ of patients under 30 and $63 \%$ of patients at least 30 years old at surgery; differences between these two age groups were smaller for changes in implant-NL angles, incisor-SNL angles, and incisor-NL angles. The differences between different age groups observed for changes in implant-SNL angles are in accordance with some previous findings [33] and in contrast to others [13, 16, 17]. The gradual decline of growth over time could explain how age at surgery influences long-term changes in implants. However, the existing literature does not unequivocally back up that theory $[13,16,17]$. We further found that the patient cohort showed a high individual variety in the extent and directions of rotational changes. Consistent with the pilot nature of this study, we did not conduct tests for statistical significance. In order to test the significance of angular changes or evaluate potential predictors, the threshold for a clinically relevant angular change has to be defined first by the scientific community. To assist future research into this area, we calculated sample sizes for theoretical thresholds of clinical relevance of 1 to $7^{\circ}$ (Supplementary Table 1).

Computer-aided standardization prior to analysis, blinded observer calibration ( $\mathrm{ICC}=99 \%$, deviation range 0 to $1^{\circ}$ ), and evaluating all measurements by the observer by two different researchers helped ensure precision and limit measurement error. Cephalometric analysis is inherently observer dependent. Intra-observer variability thus has to be minimized prior to analysis. Particular attention was given to the consistent marking of the Sella as it is a "floating" landmark; all other landmarks relevant to the analysis of angular changes are discrete structures (e.g., nasofrontal suture, implant body, central maxillary incisor). We thus believe the angular changes measured are not due to measurement error. The changes in implant-SNL angles ranging from $3^{\circ}$ counterclockwise to $4^{\circ}$ clockwise are not so substantial as to prevent implant placement starting at early adulthood. Nevertheless, the data give support to previous work [16-18] highlighting the relevance of continuous craniofacial growth in implant dentistry. It remains open at what threshold angular changes become relevant to the patient; the present study did not evaluate that as the possibility of angular changes first had to be confirmed. While vertical changes are noticed by over $60 \%$ of affected patients, they are not necessarily dissatisfied as a result $[16$, 18]. Nevertheless, the esthetics of implant restorations in the anterior maxilla are highly relevant to patients. It is thus reasonable to assume that angular changes in the esthetic zone could cause a high degree of dissatisfaction.

Limitations of the present pilot study include its retrospective design, its relatively small sample size, and its reliance on two-dimensional radiographic imaging with the inherent limitations of lateral cephalography (e.g., double contours). Alternatives to lateral cephalometry include threedimensional cone beam computer tomography. However, metal streak artifacts associated with computer tomography could make it difficult to accurately measure implant angles. Three-dimensional magnetic resonance cephalometry [34] could be utilized to overcome the potential limitations associated with the use of lateral cephalograms [35, 36]. The increasing amount of data supporting changes in implants placed in adults underscores the importance of future research into this field. Further studies with a prospective study design could take advantage of higher sample sizes and threedimensional cephalometry to gain a more profound understanding of growth processes in adulthood and better evaluate angular implant changes in the anterior maxillae of adults. In the present study, regression analysis failed to identify significant explanatory factors for the observed changes in implantSNL angles. Nevertheless, the findings should be considered relevant and basically favorable because while we showed that angular changes can occur in implants over the course of adulthood, their scale does not indicate that we should reconsider implant therapy starting at early adulthood.

\section{Conclusions}

Within the limitations of this pilot study, it can be concluded that $81 \%$ of implants placed in the anterior maxillae of adult patients show angular changes in the long term, ranging between $3^{\circ}$ counterclockwise and $4^{\circ}$ clockwise with reference to the SNL. Our findings give support to previous work describing the effects of continuous craniofacial growth in implant dentistry.

Acknowledgments The content is solely the responsibility of the authors and does not necessarily represent the official views of the Medical University of Vienna. The authors thank Mr. Stefan Lettner for the statistical analysis. All authors agree to be accountable for all aspects of the work. The present study did not receive any funding.

Funding Information Open access funding provided by Medical University of Vienna.

\section{Compliance with ethics standards}

Conflict of interest The authors declare that they have no conflict of interest.

Ethics approval All procedures performed in studies involving human participants were in accordance with the ethical standards of the institutional and/or national research committee and with the 1964 Helsinki declaration and its later amendments or comparable ethical standards.

Informed consent Informed consent was obtained from all individual participants included in the study.

Open Access This article is licensed under a Creative Commons Attribution 4.0 International License, which permits use, sharing, adaptation, distribution and reproduction in any medium or format, as long as you give appropriate credit to the original author(s) and the source, provide a link to the Creative Commons licence, and indicate if 
changes were made. The images or other third party material in this article are included in the article's Creative Commons licence, unless indicated otherwise in a credit line to the material. If material is not included in the article's Creative Commons licence and your intended use is not permitted by statutory regulation or exceeds the permitted use, you will need to obtain permission directly from the copyright holder. To view a copy of this licence, visit http://creativecommons.org/licenses/by/4.0/.

\section{References}

1. Andreasen JO, Borum MK, Jacobsen HL, Andreasen FM (1995) Replantation of 400 avulsed permanent incisors. 4. Factors related to periodontal ligament healing. Endod Dent Traumatol 11(2):7689

2. Schroeder A, van der Zypen E, Stich H, Sutter F (1981) The reactions of bone, connective tissue, and epithelium to endosteal implants with titanium-sprayed surfaces. J Maxillofac Surg 9(1):1525

3. Oesterle LJ, Cronin RJ, Ranly DM (1993) Maxillary implants and the growing patient. Int J Oral Maxillofac Implants 8(4):377-387

4. Odman J, Grondahl K, Lekholm U, Thilander B (1991) The effect of osseointegrated implants on the dento-alveolar development. A clinical and radiographic study in growing pigs. Eur J Orthod 13(4): 279-286

5. Björk A, Helm S (1967) Prediction of the age of maximum puberal growth in body height. Angle Orthod 37(2):134-143

6. Fudalej P, Kokich VG, Leroux B (2007) Determining the cessation of vertical growth of the craniofacial structures to facilitate placement of single-tooth implants. Am J Orthod Dentofac Orthop 131(4 Suppl):S59-S67

7. Ross AH, Williams SE (2010) Craniofacial growth, maturation, and change: teens to midadulthood. J Craniofac Surg 21(2):458-461

8. Forsberg CM, Eliasson S, Westergren H (1991) Face height and tooth eruption in adults - a 20-year follow-up investigation. Eur J Orthod 13(4):249-254

9. Bishara SE, Treder JE, Jakobsen JR (1994) Facial and dental changes in adulthood. Am J Orthod Dentofac Orthop 106(2):175-186

10. Heij DG, Opdebeeck H, van Steenberghe D, Kokich VG, Belser U, Quirynen M (2006) Facial development, continuous tooth eruption, and mesial drift as compromising factors for implant placement. Int J Oral Maxillofac Implants 21(6):867-878

11. Ledermann PD, Hassell TM, Hefti AF (1993) Osseointegrated dental implants as alternative therapy to bridge construction or orthodontics in young patients: seven years of clinical experience. Pediatr Dent 15(5):327-333

12. Brugnolo E, Mazzocco C, Cordioll G, Majzoub Z (1996) Clinical and radiographic findings following placement of single-tooth implants in young patients-case reports. Int J Periodontics Restorative Dent 16(5):421-433

13. Bernard JP, Schatz JP, Christou P, Belser U, Kiliaridis S (2004) Long-term vertical changes of the anterior maxillary teeth adjacent to single implants in young and mature adults. A retrospective study. J Clin Periodontol 31(11):1024-1028

14. Thilander B, Odman J, Jemt T (1999) Single implants in the upper incisor region and their relationship to the adjacent teeth. An 8-year follow-up study. Clin Oral Implants Res 10(5):346-355

15. Daftary F, Mahallati R, Bahat O, Sullivan RM (2015) Craniofacial growth in adults and its implications for implant reconstruction. In Dental Implant Complications, S.J. Froum (Ed.). https://doi.org/10. 1002/9781119140474.ch26
16. Cocchetto R, Pradies G, Celletti R, Canullo L (2019) Continuous craniofacial growth in adult patients treated with dental implants in the anterior maxilla. Clin Implant Dent Relat Res 21(4):627-634

17. Chang M, Wennström JL (2012) Longitudinal changes in tooth/ single-implant relationship and bone topography: an 8-year retrospective analysis. Clin Implant Dent Relat Res 14(3):388-394

18. Andersson B, Bergenblock S, Fürst B, Jemt T (2013) Long-term function of single-implant restorations: a 17- to 19-year follow-up study on implant infraposition related to the shape of the face and patients' satisfaction. Clin Implant Dent Relat Res 15(4):471-480

19. Sanders JO, Qiu X, Lu X, Duren DL, Liu RW, Dang D, Menendez ME, Hans SD, Weber DR, Cooperman DR (2017) The uniform pattern of growth and skeletal maturation during the human adolescent growth spurt. Sci Rep 7(1):16705

20. Tanner JM, Whitehouse RH, Marubini E, Resele LF (1976) The adolescent growth spurt of boys and girls of the Harpenden growth study. Ann Hum Biol 3(2):109-126

21. Hägg U, Taranger J (1981) Dental emergence stages and the pubertal growth spurt. Acta Odontol Scand 39(5):295-306

22. Heuberer S, Dvorak G, Mayer C, Watzek G, Zechner W (2015) Dental implants are a viable alternative for compensating oligodontia in adolescents. Clin Oral Implants Res 26(4):e22-e27

23. Cronin RJ, Oesterle LJ, Ranly DM (1994) Mandibular implants and the growing patient. Int J Oral Maxillofac Implants 9(1):55-62

24. Thilander B, Odman J, Groteborg K, Friberg B (1994) Osseointegrated implants in adolescents. An alternative in replacing missing teeth? Eur J Orthod 16(2):84-95

25. Nairn RI (1973) Lateral and protrusive occlusions. J Dent 1(4):181-187

26. Belser UC et al (2004) Outcome analysis of implant restorations located in the anterior maxilla: a review of the recent literature. Int J Oral Maxillofac Implants 19(Suppl):30-42

27. Gribel BF, Gribel MN, Frazão DC, McNamara JA Jr, Manzi FR (2011) Accuracy and reliability of craniometric measurements on lateral cephalometry and 3D measurements on CBCT scans. Angle Orthod 81(1):26-35

28. Jarabak JR, Fizzell JA (1963) Technique and treatment with lightwire edgewise appliances; light deferential forces in clinical orthodontics. CV Mosby Co, Saint Louis

29. Sarhan OA (1995) Sella-Nasion line revisited. J Oral Rehabil 22(12):905-908

30. Thilander B, Odman J, Grondahl K, Lekholm U (1992) Aspects on osseointegrated implants inserted in growing jaws. A biometric and radiographic study in the young pig. Eur J Orthod 14(2):99-109

31. Thilander B, Odman J, Lekholm U (2001) Orthodontic aspects of the use of oral implants in adolescents: a 10-year follow-up study. Eur J Orthod 23(6):715-731

32. Jemt T, Ahlberg G, Henriksson K, Bondevik O (2007) Tooth movements adjacent to single-implant restorations after more than 15 years of follow-up. Int J Prosthodont 20(6):626-632

33. Schwartz-Arad D, Bichacho N (2015) Effect of age on single implant submersion rate in the central maxillary incisor region: a long-term retrospective study. Clin Implant Dent Relat Res 17(3):509-514

34. Juerchott A, Saleem MA, Hilgenfeld T, Freudlsperger C, Zingler S, Lux CJ, Bendszus M, Heiland S (2018) 3D cephalometric analysis using magnetic resonance imaging: validation of accuracy and reproducibility. Sci Rep 8(1):13029

35. Damstra J et al (2010) Reliability and the smallest detectable differences of lateral cephalometric measurements. Am J Orthod Dentofac Orthop 138(5):546.e1-546.e8 discussion 546-7

36. Devereux L, Moles D, Cunningham SJ, McKnight M (2011) How important are lateral cephalometric radiographs in orthodontic treatment planning? Am J Orthod Dentofac Orthop 139(2):e175-e181

Publisher's note Springer Nature remains neutral with regard to jurisdictional claims in published maps and institutional affiliations. 